\title{
Lifestyle changes: A social psycho- logical perspective with reference with cigarette smoking among adolescents
}

\author{
Mark Morgan \\ St. Patrick's College, Dublin \\ \& \\ Joel W. Grube \\ Prevention Research Center, Berkeley, USA
}

This paper examines the implications of social psychological influences on smoking behaviour for models of prevention. The main factors associated with initiation to and maintenance of smoking are examined with particular reference to normative influences, expectations about consequences, and personality and social variables. Each of these factors will be shown to inform approaches to prevention. In turn, the evidence for the effectiveness of these prevention models is outlined. Finally, the major questions for further development of the approaches to prevention are examined.

Common-sense approaches to changes in life style have been shown to be notoriously wrong. The research demonstrating that smoking was likely to cause a range of diseases, including coronary heart disease (CHD) (Cleary \& Shelley, 1983) was expected to change smoking behaviour in the long-term. It was commonly believed that established smokers were unlikely to be able to kick the habit, because of their addiction, but that young people would not take up the habit knowing that it could cause such negative outcomes. The result of the campaigns to stop smoking have shown that the commonsense view was wrong on both scores. Established smokers have found it relatively easy to discard their 'addiction', yet young people continued to behave 'irrationally' in taking up the smoking habit (Grube \& Morgan, 1986). The current level of smoking uptake by adolescents is still quite similar to 25 years ago.

This pattern of outcomes might easily be predicted in terms of the effects of perceived consequences on behaviour (Bandura, 1986). The long-term consequences associated with smoking, such as lung cancer and health damage which were so strongly featured in the first anti-smoking

Correspondence address: Dr Mark Morgan, St. Patrick’s College, Dublin 9, Republic of Ireland.

This article is a reproduction of that published in: Irish Journal of Psychology, 1994, 15(1) pp.179-190. Pagination may not match that of the original. 
campaigns, are so dim and distant in the lives of children and adolescents as to make them weak motivators. On the other hand, 'looking cool' and feeling more popular are short-term outcomes that are much more salient than the long-term effects.

This paper examines a number of issues related to the major factors associated with changes in behaviour of relevance to health, with particular reference to smoking among adolescents. We then illustrate how some of the findings indicate the potential for smoking prevention and describe the results of some of the interventions.

\section{INFLUENCES ON ADOLESCENT SMOKING}

A theoretical framework (Grube \& Morgan, 1986) which would seem to predict and explain the initiation to and maintenance of smoking behaviour among adolescents is described in Figure 1. The factors are ordered from left to right to indicate the extent to which they are hypothesised to influence smoking directly or through other variables. The distal variables appear in the left hand column; these are thought to influence smoking only indirectly. Included in this category are genetic characteristics and background influences such as age, social background and gender. Variables of an intermediate nature appear in the middle columns. These include normative influences, expectancies regarding smoking use, attitude to smoking as well as perceived availability. Finally, the present model assumes that only two variables directly influence smoking, i.e., intention and habit.

The theoretical framework presented here has been heavily influenced by two theoretical positions, i.e., the theory of reasoned action (Ajzen \& Fishbein, 1980) and cognitive social learning theory (Bandura, 1986). The theory of reasoned action assumes social behaviours like smoking are largely the result of rational decision making processes. Consistent with this assumption behavioural intentions are seen as to be one of the primary determinants of smoking. In turn, the theory proposes that intentions are the direct result of attitudes, expectancy value beliefs and normative influences.

However, the present model includes a wider range of variables than do these models. For example, the Azjen and Fishbein model has a particularly restrictive conception of the influences within the normative domain - a point which is discussed further below. The other significant difference is that the influences proposed here are regarded as being interactive in some cases, whereas Ajzen and Fishbein do not consider such effects.

This article is a reproduction of that published in: Irish Journal of Psychology, 1994, 15(1) pp.179-190. Pagination may not match that of the original. 
Figure 1. Hypothesised influences an adolescent substance use (reprinted with permission from Grube and Morgan, 1986, p.27).

\begin{tabular}{|c|c|c|c|c|}
\hline \multicolumn{2}{|l|}{ DISTAL } & \multicolumn{2}{|l|}{ INTERMEDIATE } & \multirow{2}{*}{$\begin{array}{l}\text { IMMEDIATE } \\
\text { Behavioural } \\
\text { Intention }\end{array}$} \\
\hline $\begin{array}{l}\text { Background } \\
\text { characteristics }\end{array}$ & Personality/Values & Expectancy-Value Beliefs & Attitude & \\
\hline Gender & $\begin{array}{l}\text { Value for } \\
\text { independence }\end{array}$ & Perceived consequences & $\begin{array}{l}\text { Evaluation } \\
\text { of behaviour }\end{array}$ & $\begin{array}{l}\text { Subjective } \\
\text { likelihood }\end{array}$ \\
\hline Geographic location & $\begin{array}{l}\text { Extroversion/ } \\
\text { sensation seeking }\end{array}$ & $\begin{array}{l}\text { Evaluation of perceived } \\
\text { consequences }\end{array}$ & & \\
\hline \multirow[t]{3}{*}{ Age } & Self-esteem & & & \\
\hline & Tolerance of deviance & & & \\
\hline & Internality-externality & & & \\
\hline $\begin{array}{l}\text { Physiological- } \\
\text { Genetic Factors }\end{array}$ & Social Bonding & $\begin{array}{l}\text { Substance Use } \\
\text { Environment }\end{array}$ & Perceived Availability Habit & \\
\hline $\begin{array}{l}\text { Genetic bases } \\
\text { for personality }\end{array}$ & Attachment to family & Behaviours of parents & Perceived access & $\begin{array}{l}\text { Cognitive } \\
\text { scripts }\end{array}$ \\
\hline $\begin{array}{l}\text { Susceptibility } \\
\text { to drug }\end{array}$ & Attachment to peers & Behaviours of peers & $\begin{array}{l}\text { Expected cost } \\
\text { /resources }\end{array}$ & $\begin{array}{l}\text { Conditioned } \\
\text { behaviours }\end{array}$ \\
\hline \multirow{4}{*}{$\begin{array}{l}\text { Susceptibility } \\
\text { to addiction }\end{array}$} & Attachment to religion & Attitudes of parents & Knowledge & \\
\hline & Attachment to school & Attitudes of peers & & \\
\hline & & Social/legal sanctions & & \\
\hline & & Media & & \\
\hline Socio-Cultural Factors & Previous Behaviour & Dependency & Normative beliefs & \\
\hline $\begin{array}{l}\text { Meaning and role } \\
\text { of substance use }\end{array}$ & Past substance use & Tolerance & $\begin{array}{l}\text { Perception of parental } \\
\text { behaviour }\end{array}$ & \\
\hline \multirow[t]{3}{*}{ Cultural definitions } & & $\begin{array}{l}\text { Physical } \\
\text { dependence }\end{array}$ & Perception of peer behaviour & \\
\hline & & Adaptive & Perception of parental attitudes & \\
\hline & & & Perception of peers attitudes & \\
\hline
\end{tabular}

This article is a reproduction of that published in: Irish Journal of Psychology, 1994, 15(1) pp.179-190. Pagination may not match that of the original. 
A number of influences that are considered to be at the intermediate level of influence are examined here. In each case the evidence for the significance of the influence is examined and some implications for interventions are addressed.

\section{NORMATIVE INFLUENCES}

There are least two types of normative influence that are influential. Perceived approval consists of beliefs about the extent to which parents or peers may approve or disapprove of a particular behaviour while behavioural norms consist of beliefs about the extent to which significant others engage in the behaviour themselves. The various kinds of normative beliefs may or may not be consistent with each other. Parents, for example, may be seen as proscribing smoking for their children while at the same time conveying social acceptance of this behaviour through their own smoking. A study by Grube, Morgan and McGree (1986) examined the relative importance of behavioural norms and perceived approval in the context of the smoking behaviour of Irish school children and college students. In both samples, it was clear that behavioural norms were distinct from perceived approval. Furthermore, they were better predictors of smoking behaviour. The important implication of this is that the research that has failed to consider behavioural norms may have led to an under-estimation of the contribution of normative influences as determinants of behaviour, since the results may have been due to the fact that only measures of perceived approval were included.

From the point of view of cigarettes smoking, an important question concerns the extent to which the influences associated with normative influences change during adolescence. This was the focus of the study by Morgan and Grube (1989) with a sample of 3000 Irish post-primary school pupils. The results showed that normative influences on smoking behaviour increased up to age 15-16 years and then declined. This curvilinear pattern seemed to have been largely due to the rise and decline of peer influences over these years. Interestingly, however, the influence of parents (both in terms of parental example and approval) was constant over this period.

Given that peer influence has been established as a major facet of normative influences, most of the studies have lacked a rationale regarding how peers should be identified and how predictions might be made on the relative influence of one group of age-mates as opposed to another. Morgan and Grube (1991) proposed that influence would depend heavily on closeness of peer relationships. In a longitudinal study, they sought to determine the extent to which persons identified as the 'best friend' and

This article is a reproduction of that published in: Irish Journal of Psychology, 1994, 15(1) pp.179-190. Pagination may not match that of the original. 
'other good friends' and ' young people my age' are important influences in adolescent smoking and other substance use. In support of the closeness hypothesis the influences associated with peers identified by respondents as friends were better predictors of smoking than those of same-aged peers while the person identified as the best friends was especially influential. However, there were important differences in the peer influences associated with maintenance of smoking as opposed to initiation. It emerged that several good friends were influential (through example and approval) in initiation while the best friend had a critical role in the maintenance of smoking behaviour.

\section{NORMATIVE EDUCATIONAL APPROACHES TO PREVENTION}

These approaches arc based on the evidence described above on the relationship between normative support for smoking and actual smoking behaviour. In general, normative education programmes are designed to make salient to young people the message that prevailing norms regarding smoking are more conservative than many young people think is the case. The components of normative education often include providing indicators that smoking is not as widespread among peers as children may think, encouragement for young people to make public commitments not to smoke and the depiction of smoking as socially unacceptable.

A recent study by Hansen and Graham (in press) showed that correcting erroneous perceptions among students about the prevalence and acceptability of alcohol, actually deterred the onset of alcohol consumption. Specifically, it was shown that normative education reduced the incidence of drunkenness and the prevalence of alcohol problems among students in junior high schools in California. Furthermore, Hansen and Graham have demonstrated that such education was more effective than other treatments in reducing the onset of drinking behaviour.

While these initial tests of the effects of normative education are worthwhile and would seem to be especially promising in delaying the onset of smoking, some considerations about the nature of peer influence are worth considering. First, the evidence reviewed above suggests that information about same-age peers should have relatively little influence compared to the closer peer group (friends and the 'best friend'). A second important factor to note is that there is a well-documented bias whereby people to perceive their own opinions and behaviours as more typical than they are in reality. This research on the so-called 'false-consensus effect' (Rodin \& Salovey, 1989) has also demonstrated that beliefs about the prevalence of behaviours like smoking and drinking are not easily modified

This article is a reproduction of that published in: Irish Journal of Psychology, 1994, 15(1) pp.179-190. Pagination may not match that of the original. 
among substance users. In other words, while it is easy to convince nonsmokers that smoking is unacceptable and that only a minority of the same-aged population indulge in the habit, the deeper significance of the behaviour for smokers may make them less ready to accept the veracity of such assertions. Thus, while it may well be that establishing conservative norms may indeed be an effective means for bringing about a reduction in adolescent smoking, there would seem to be a real difficulty providing information that is credible enough to create such norms.

Normative education approaches have some extremely important implication for teachers, parents and health professionals involved with efforts to reduce behaviours like smoking, drinking and other drug use. Many interventions suggest that these behaviours (i.e., underage drinking and adolescent smoking) are very prevalent. Usually such information is considered to be 'neutral information' that provides a context for later skill training and/or information about consequences. What is not frequently realised is that such information may indicate that there are supporting norms for such behaviour among young people and this in turn may have the effect of reducing positive effects that the programme might otherwise have had. Thus, the information on normative influences may not only indicate the direction for programmes for prevention but may also suggest components of such programmes that should be avoided.

\section{EXPECTATION OF CONSEQUENCES}

Expectations relating to consequences have two components. Firstly, there is the perception of the likelihood that a given behaviour will have specific personal consequences for the individual and secondly there is the evaluation of these consequences. An example of the first component would be the probability that a young person thinks that smoking will harm their health, while the second component refers to their judgement about the importance of such consequences, i.e., how important damaging their health is to them. Two distinctions are important in the consideration of the effects of consequences, i.e., between long-term and short-term consequences and between positive and negative outcomes. 'Damage to health' and 'becoming addicted' are relatively long-term consequences of smoking while 'having bad breath' or 'smelly clothes' are outcomes that tend to occur in the short-term as a result of smoking. All of these outcomes are negative in the sense that they are undesired consequences. In contrast, outcomes such as 'becoming popular', 'forgetting one's troubles' and 'looking cool' can be regarded as positive consequences since they are part of the motivation for smoking behaviour.

This article is a reproduction of that published in: Irish Journal of Psychology, 1994, 15(1) pp.179-190. Pagination may not match that of the original. 
The relationship between beliefs about consequences and smoking behaviour have been substantiated in a number of studies. For example, smokers are less likely than nonsmokers to believe that smoking increases their chances of getting lung cancer and harms their health. Conversely, they are more likely to believe that it will increase their popularity, make them feel more relaxed and help them concentrate (Bauman \& Chenoweth, 1984). Similarly, smokers evaluate the negative consequence of smoking less negatively than do nonsmokers and the positive consequences more positively (Budd \& Spencer, 1984).

While these results are predicted by most rational and commonsense analyses of smoking there are two findings that may be of special relevance. These concern the relative importance of short-term as opposed to long-term consequences of smoking. A number of studies (e.g., Grube, McGree \& Morgan, 1984) have shown that beliefs about short-term consequences tend to be more strongly associated with smoking than are beliefs about long-term consequences. Thus, the belief that cigarettes will lead to smelly breath is a stronger predictor of smoking than the belief that smoking damages health. The other interesting point is that differences between smokers and nonsmokers in beliefs about health consequences do not come about when the smoking of others rather than own smoking was the focus (Kristiansen, Harding \& Eiser, 1983). It emerged that smokers were just as likely as nonsmokers to believe that smoking was related to cancer or cardiovascular disease for others. This finding reinforces the importance of investigating personalised beliefs rather than general beliefs. This outcome ties in with the work on perception of risk and vulnerability. The general finding is that people tend to underestimate their own risk relative to other people for illnesses and other negative life events (Rodin \& Salovey, 1989). This can have important consequences for health since perceived susceptibility is associated with greater motivation for prevention.

Research on consequences has important implications for prevention. One systematic approach to deterring the onset of smoking is to provide young people with direct evidence of the physiological consequences of smoking (Perry, Killeen, Tetch, Slinkard \& Danaher, 1980). In some of the studies, attachment to a heart monitor has been used to demonstrate that smoking cigarettes increases heart rate and blood pressure. In other studies the undesirable effects of other substances use for family and other interpersonal relationships have been demonstrated (Ellickson, 1984).

A recent study featuring a strong emphasis on short and long-term consequences examined was carried out in primary schools in disadvantaged areas of Dublin (Morgan, Doorley, Hynes \& Joy, in press). The

This article is a reproduction of that published in: Irish Journal of Psychology, 1994, 15(1) pp.179-190. Pagination may not match that of the original. 
programme included integration with other school subjects as well as parental involvement and visits by Health Board personnel. Compared to matched control groups, the classes in which the programme was piloted showed less positive attitudes towards smoking and greater awareness of the dangerous consequences of smoking

\section{PERSONALITY AND SOCIAL FACTORS}

In addition to the normative influences and beliefs about consequences, a range of other factors are known to be associated with smoking behaviour among adolescents. Much attention has been given to the relationship between smoking and various kinds of problem behaviour. For example, several studies have shown that young people who smoke at a relatively early age tend to be involved in other deviant behaviours such as drinking, illicit drug-use and truancy (Jessor \& Jessor, 1977). In addition, in those studies that have examined attitudes towards deviance, it has been shown that acceptance of deviant behaviour tends to relate quite strongly to smoking behaviour (Brook, Whiteman \& Gordon, 1983).

There is also evidence that social bonding to conventional institutions has a restraining influence on smoking (Kaplan, Martin \& Robbins, 1984). The social bonding perspective suggest that if an individual has a commitment to a social institution, then they are less likely to engage in behaviours that are deviant and rebellious. In the context of adolescent smoking, this idea has been explored in relation to commitment to family, school, church and religion. The basic idea is that to the extent that an individual values membership of those institutions, he or she will be less likely to be involved in various kinds of antisocial behaviour. While smoking per se is not illegal, smoking by young people can be considered to be deviant and likely to be influenced by adherence to the norms of such institutions.

The available literature strongly supports the finding that commitment to school is negatively related to smoking behaviour. Studies in France and Israel by Adler and Kandel (1981) showed that interest in schoolwork and rated importance of such activities were negatively related to frequency of smoking. Grube and Morgan (1986) also found that Dublin students rated importance of school and their rating of own academic achievement were both negatively related to smoking. Similar findings are presented by Ensminger, Brown and Kellam (1982) who note however that the relationship with commitment is stronger for other substances (including alcohol and illegal drugs) than for cigarette smoking.

This article is a reproduction of that published in: Irish Journal of Psychology, 1994, 15(1) pp.179-190. Pagination may not match that of the original. 


\section{RISK-FOCUSED INTER VENTIONS}

A relatively promising approach to the prevention of adolescent substance use is through a risk-focused intervention (Hawkins, Catalano \& Miller, 1992). Such an approach requires a number of steps: (i) identification of high-risk factors for substance use, (ii) identification of the strategies that are effective in reducing such risk factors, and (iii) application of such methods to high-risk groups. For example, low family bonding, problem behaviours, tolerance of deviance and perceived peer approval have all been shown to be related to increased substance abuse. If strategies could be identified to reduced these factors, then by implication these same strategies could be used to prevent substance use, including smoking.

It must be admitted that few studies have gone through all of the steps required in this approach. Moreover, many risk factors are either not amenable to modification (e.g., genetic factors) or extremely difficult to change (e.g., parental behaviour). However, various studies taken together testify to the promise of the approach. There is considerable evidence that aggression and other problem behaviours in the primary school years are associated with increased risk of substance use during adolescence. In turn, it has been suggested that educational strategies designed to enhance social competencies during childhood might reduce the risk of later drug abuse (Hawkins et al., 1992). For example, it might be that children who are aggressive and disruptive are rejected by their peers because they are deficient in basic interpersonal skills that can be taught. Social competence promotion approaches have used a number of methods. For example, socially rejected youths have been taught social interaction skills to increase the frequency of their social interactions (Ladd \& Asher, 1985). However, while such programmes have been tested in relation to their effects on short-term outcomes, such as adjustment at school and relationship with peers, only a small number of studies have examined effects on later substance use.

This approach to prevention of the onset of smoking merits attention. A riskfocused basis is not concerned with short-term consequences or with quick and easy manipulations. Rather, it attempts to prevent the onset of problems by addressing the developmental factors that are crucially related to substance-abuse problems. The real difficulties with the approach lie in the fact that the factors being addressed are extremely difficult to control since they involve matters like parental behaviours, enhancement of school-achievement and learning to use alternatives to aggression. It merits considerably more research attention in the future.

This article is a reproduction of that published in: Irish Journal of Psychology, 1994, 15(1) pp.179-190. Pagination may not match that of the original. 


\section{CONCLUSIONS AND FUTURE DIRECTIONS}

A number of conclusions are warranted on the basis of the studies reviewed above. Firstly, the understanding of the processes underlying the uptake of smoking by young people has resulted in systematic effort to prevent its onset. This constitutes a considerable advance on the mere information approach of 20 years ago. Secondly, and in line with the multi-determined nature of smoking, no single approach has been demonstrated to be vastly superior to any other. A great deal seems to depend on the effectiveness of the delivery of the programme. A related point is that some programmes, supposedly based on one kind of influence, may have their impact in ways additional to those predicted by the programme's focus. For example, it has been argued that social skills are effective because they draw attention to the conservative nature of norms surrounding such behaviour.

Finally, the question of the interaction of educational measures with other approaches should be examined. Educational approaches are geared to influencing the demand for cigarettes and other substances; there are grounds for thinking that curtailment of the supply of cigarettes to very young people might be a worthwhile initiative. In fact, the law in relation to sale of cigarettes to young people is rather strong. Under Section 3 of the Tobacco (Health and Protection) Act 1988 of the Republic of Ireland, any person '...who sells or makes available any tobacco products to a person under the age of 16 years, whether for his own use or otherwise...shall be guilty of an offence (carrying a) Penalty $£ 500$.' In addition, Section 4 of the same Act forbids the selling of cigarettes other than in packs of 10 or 20 . Obviously important questions concern the enforcement of these laws. In our view, the existing laws could make an important contribution to reducing the supply of cigarettes to young people. Besides the effectiveness per se of such a measure, there would be important consequences for perceived norms about smoking. Thus legal initiatives and health promotion strategies incorporating a social-psychological perspective may provide complementary strategies in the reduction of cigarette smoking among adolescents.

\section{ACKNOWLEDGEMENTS}

Thanks are due to Dr Hannah McGee for her encouragement and assistance in the preparation of this paper and to Sergeant Michael Egan for his advice on the legal measures relating to sale of cigarettes to minors.

This article is a reproduction of that published in: Irish Journal of Psychology, 1994, 15(1) pp.179-190. Pagination may not match that of the original. 


\section{REFERENCES}

Adler, I. S. \& Kandel, D.B. (1981). A cross-cultural comparison of socio-psychological factors in alcohol use among adolescents in Israel, France and the United States, Journal of Youth and Adolescence, 11, 89-113.

Ajzen, I. \& Fishbein, M. (1980). Understanding Attitudes and Predicting Social Behaviour. Englewood Cliffs, NJ: Prentice-Hall.

Bandura, A. (1986). Social Foundations of Thought and Action. Englewood Cliffs, NJ: Prentice Hall.

Bauman, K.E. \& Chenoweth, R.L. (1984). The relationship between the consequences adolescents expect from smoking and their behaviour: A panel study of adolescent cigarette smoking. Journal of Applied Social Psychology, 14, 28-41.

Brook, J.S., Whiteman, M. \& Gordon, A.S. (1983). Stages of drugs use in adolescence: Personality, peer and family correlates. Developmental Psychology, 19, 269-277.

Budd, R. J. \& Spencer, C.P. (1984). Predicting undergraduates' intentions to drink. Journal of Studies on Alcohol, 45, 179-183.

Cleary, A. \& Shelley, E. (1983). Smoking and health - The facts in Ireland. Irish Medical Journal, 76 (Supplement 12), 1 -29.

Ellickson, P.L. (1984). Project Alert: A Smoking and Drug Prevention Programme. Santa Monica: Rand Corporation.

Ensminger, M.E., Brown, C.H. \& Kellam, S.G (1982) Sex differences in antecedents of substance use among adolescents. Journal of Social Issues, 38, 25-42.

Grube, J.W., McGree, S. \& Morgan, M. (1984). Smoking behaviours, intentions and beliefs among Dublin primary school children. The Economic and Social Review, $15,265-288$.

Grube, J.W. \& Morgan, M. (1986). Smoking, drinking and other drug use among Dublin post-primary schoolpupils, Dublin: Economic and Social Research Institute.

Grube, J.W., Morgan, M. \& McGree, S. (1986). Attitudes and normative beliefs as predictors of smoking intentions and behaviours: A test of three models. British Journal of Social Psychology, 25, 81-93.

Grube, J.W. \& Morgan, M. (1990). The development and maintenance of smoking drinking and other drug use among Dublin post-primary pupils. Dublin: Economic and Social Research Institute.

Hansen, W.B. \& Graham, J.W. (in press) Peer pressure training versus establishing conservative norms in preventing alcohol, marijuana, and cigarette use among adolescents. Journal of Preventive Medicine.

Hawkins, J.D. Catalano, R.F. \& Miller, J.Y. (1992). Risk and protective factors for alcohol and other drug problems in adolescence and early childhood: Implications for substance abuse prevention. Psychological Bulletin, 112, 64-105.

Kaplan, H.B., Martin, S.S. \& Robbins, C. (1984). Pathways to adolescent drug use: Selfderogation, peer influence, weakening of social controls, and early substance use.

This article is a reproduction of that published in: Irish Journal of Psychology, 1994, 15(1) pp.179-190. Pagination may not match that of the original. 
Journal of Health and Social Behaviour, 25, 270-289.

Kristiansen, C. M., Harding, C.M. \& Eiser, J.R. (1983). Beliefs about the relationship between smoking and cause of death. Basic and Applied Social Psychology, 4, 252-261.

Ladd, G.W. \& Asher, S.R. (1985). Social skills training and children's peer relations: Current issues in research and practice. In L.A. Abate \& M.A. Milan, (Eds), Handbook of Social Skills Training and Research, pp.219-244. New York: Wiley.

Jessor, R. \& Jessor, S.L. (1977). Problem Behaviour and Psycho-Social Development: A longitudinal Study of Youth. New York: Academic Press.

Morgan, M. \& Grube, J.W. (1989). Adolescent cigarette smoking: Developmental analysis of influences. British Journal of Developmental Psychology, 7, 179-189.

Morgan, M. \& Grube, J.W. (1991). Closeness and peer group influence. British Journal of Social Psychology, 30, 159 - 169.

Morgan. M., Doorley, P., Hynes, M. \& Joy, S. (in press). An evaluation of a smoking prevention programme with children from disadvantaged communities. Irish Medical Journal.

Perry, C., Killeen, J., Telch, L.A., Slinkard, L.A. \& Danaher, E.G. (1980) Modifying smoking behaviours of teenagers: A school-based intervention. American Journal of Public Health, 70, 722-725.

Rodin, J. \& Salovey, P. (1989). Health Psychology. Annual Review of Psychology, 40, 533-579.

Dr Mark Morgan lectures in psychology at St. Patrick's College, Dublin. His research interests include adolescent substance use and evaluation of related prevention programmes, and literacy and motivation. Dr Joel W. Grube is a senior research scientist with the Prevention Research Center, Berkeley, California. He was formerly a research officer at the Economic and Social Research Institute, Dublin. His research interests include substance use, media influences on attitudes and beliefs and models of attitude change.

This article is a reproduction of that published in: Irish Journal of Psychology, 1994, 15(1) pp.179-190. Pagination may not match that of the original. 